\title{
Unit of Tissue Culture Infective Dose
}

National Cancer Institute

\section{Source}

National Cancer Institute. Unit of Tissue Culture Infective Dose. NCI Thesaurus. Code C70486.

A unit for measuring infectious activity of biologic product such as vaccine or pathogen defined in tissue culture assay. 